\title{
Morbidly Obese Patients-Who Undergoes Bariatric Surgery?
}

\author{
Gunn Signe Jakobsen • Dag Hofsø • Jo Røislien • \\ Rune Sandbu • Jøran Hjelmesæth
}

Received: 20 July 2009 /Accepted: 1 December 2009/Published online: 5 January 2010

(C) The Author(s) 2009. This article is published with open access at Springerlink.com

\begin{abstract}
Background Bariatric surgery particularly benefits patients with obesity-related comorbidities such as type 2 diabetes and obstructive sleep apnea. We aimed to examine whether the variables that influence treatment choice differ between morbidly obese patients undergoing bariatric surgery and those opting for conservative treatments.

Methods A total of 505 consecutive morbidly obese patients (72\% women; mean (SD) age 42 (12) years) who attended our tertiary care center between December 2005 and February 2007 were examined by a multidisciplinary team and offered surgical or conservative treatment. The chi-square test, independent samples $t$ test, and multiple logistic regression were used in the statistical analyses.

Results A total of 249 (49\%) patients underwent bariatric surgery. When compared to the conservative group of patients, the surgery group was characterized by a significantly higher mean (SD) BMI (46.5(6.2) vs. $43.2(5.5) \mathrm{kg} / \mathrm{m}^{2}$, $p<0.001$ ), earlier onset of obesity ( $40 \%$ vs. $26 \%$ before 12 years of age, $p<0.001)$, and lower age (41(11) vs. 44 (13) years, $p=0.002$ ). In contrast, the groups did not differ significantly with respect to gender or obesity-related comorbidities. After adjustments for gender, age, onset of obesity, and the number of comorbidities, multiple regression revealed that patients with BMI $40-50$ or $>50 \mathrm{~kg} / \mathrm{m}^{2}$ had between $3(\mathrm{OR}=3.0 ; 95 \% \mathrm{CI} 1.9-4.9, p<0.001)$ and 6 $(\mathrm{OR}=5.7 ; 95 \%$ CI 3.0-11.0, $p<0.001)$ times the chance of undergoing bariatric surgery when compared to patients with a BMI $<40 \mathrm{~kg} / \mathrm{m}^{2}$ (reference).
\end{abstract}

G. S. Jakobsen $(\triangle) \cdot$ D. Hofs $\varnothing \cdot J$. Røislien $\cdot$ R. Sandbu

J. Hjelmesæth

Morbid Obesity Centre, Vestfold Hospital Trust,

Box 2168, 3103 Tønsberg, Norway

e-mail: gunn.signe.jakobsen@siv.no

e-mail: gunn.signe.jakobsen@gmail.com
Conclusion Our data indicates that increasing BMI rather than obesity-related comorbidities, predicted treatment choice in morbidly obese patients.

Keywords Obesity · Morbid · Therapy · Bariatric surgery · Comorbidity

\section{Introduction}

The prevalence of obesity is increasing worldwide [1] and Norway is no exception; currently $20 \%$ of the population is obese (BMI $\geq 30 \mathrm{~kg} / \mathrm{m}^{2}$ ) [2]. Morbid obesity (BMI $\geq 40 \mathrm{~kg} / \mathrm{m}^{2}$ or BMI $\geq 35 \mathrm{~kg} / \mathrm{m}^{2}$ with at least one obesity-related comorbidity) is associated with both increased susceptibility to a wide range of diseases and increasing mortality rates [3]. Long-term follow-up studies have demonstrated the beneficial effects that bariatric surgery can have on obesity-related comorbidities, quality of life and survival [3-6]. Although conservative treatment is less effective than bariatric surgery in terms of weight reduction, several studies have shown the significant and durable effects which behavioral therapy, lifestyle changes, low-calorie diets, and pharmacotherapy can have on weight loss, weight maintenance [7-10], type 2 diabetes, and quality of life [11, 12].

The indications for bariatric surgery are widely accepted [13-15]. Morbidly obese patients who have attempted to lose weight by nonoperative means and who are well informed and motivated may be considered for surgery. The patient should be evaluated by a multidisciplinary team and the surgeon should have substantial experience in a clinical setting with adequate support. Lifelong medical surveillance is necessary to both support adherence to mandatory behavioral changes and to prevent micronutrient and vitamin deficiencies after surgical therapy. Only a small 
proportion of morbidly obese subjects are offered bariatric surgery, and given this the criteria for selection is of the upmost importance. Dixon has recently argued that the referral of patients with a BMI $>50 \mathrm{~kg} / \mathrm{m}^{2}$, or with a BMI $>40 \mathrm{~kg} / \mathrm{m}^{2}$ with a serious weight loss responsive comorbidity for a surgical opinion, should not be merely an option but a physician`s responsibility as best care for the patients [16].

The primary objective of this study was to examine whether the variables that influence treatment choice (level of obesity, age, weight history, and obesity-related comorbidities) differ between morbidly obese patients undergoing bariatric surgery and those opting for conservative treatment.

\section{Methods}

\section{Study Design}

This was a cross-sectional observational cohort study of consecutive treatment seeking morbidly obese patients attending the Morbid Obesity Center (MOC). Patients who underwent bariatric surgery (surgery group, SG) were compared with patients who received conservative therapy (conservative treatment group, CTG).

\section{Setting}

\section{The Public Healthcare System and Patient Rights}

The Norwegian healthcare system is public and usually free of charge for individual patients. In 2004, the Ministry of Health and Care Services acknowledged morbid obesity as an increasingly serious public health problem and instructed the five Regional Health Authorities (RHAs) to provide morbidly obese patients with an appropriate treatment choice; either conservative or surgical. Recently released national guidelines conclude that treatment seeking morbidly obese subjects shall be offered a complete diagnostic workup and startup of therapy, either conservative or surgical, in an obesity clinic based on the multidisciplinary team model [17].

\section{The Morbid Obesity Center}

The MOC is a tertiary care center founded by the SouthEastern Norway RHA, which itself serves close to one million inhabitants in the southern part of Norway. The MOC has implemented the national guidelines referred to above.

Physicians at local hospitals may refer morbidly obese patients who have undergone repeated trials of unsuccessful weight loss. All patients who are referred to the MOC undergo a thorough (up to 6 months) assessment by a multidisciplinary team consisting of an internist, a dietician, a physiotherapist, and a trained "obesity" nurse. During the first visit, the internist establishes a detailed medical history, checks previous diagnostic workups, performs a physical examination, and briefly informs the patient of further investigations and treatment alternatives. At the second visit the doctor reiterates this message, providing complete information about the possible risks and benefits of an operation and also encouraging the patient to incorporate their own values and preferences in the decision-making process. If no contraindication against surgery exists the patient and the physician together agree upon the most appropriate choice of therapy; either surgical or conservative. We perform approximately 200 bariatric operations a year and $90 \%$ of these procedures are laparoscopic gastric bypasses. Patients who do not undergo surgery are offered a variety of individual or group-based conservative treatment options, either in our outpatient clinic or at various weight loss camps. These centers have implemented motivation guidance techniques in order to provide a comprehensive intervention program which will increase physical activity and fitness, normalize eating habits and induce a weight loss of at least $5-10 \%$ during the first year.

Data from the first consultation at the MOC was extracted from a prospective database on 524 patients enrolled consecutively between November 2005 and February 2007. In order to be included in the database all patients gave written informed consent. All patient records were reviewed within 21-36 months after the first consultation at the MOC in order to assess treatment choice.

\section{Participants}

A total of 524 patients attended the MOC during the inclusion period (Fig. 1). After excluding 13 patients with a BMI $<35 \mathrm{~kg} / \mathrm{m}^{2}$ and six patients $(1 \%)$ with unknown treatment choice, 505 patients were included in the analysis. At a median (range) of 28 (21-36) months after the first consultation a total of 249 patients $(49 \%)$ had undergone surgery, while 256 patients $(51 \%)$ had been treated conservatively. A small number of patients $(8 / 511)$ were refused surgery due to either old age $(n=2)$, their lack of ability to cooperate $(n=2)$, the increased operative risk caused by previous abdominal surgery or serious comorbidity $(n=6)$, or a combination of increased operative risk and comorbidity which was not likely to improve after bariatric surgery $(n=3)$. These patients accepted the doctor's decision and were included in the conservative treatment group. One patient was advised by the doctor to try conservative treatment, but decided to have surgery at a private clinic. This patient was included in the surgery group. 


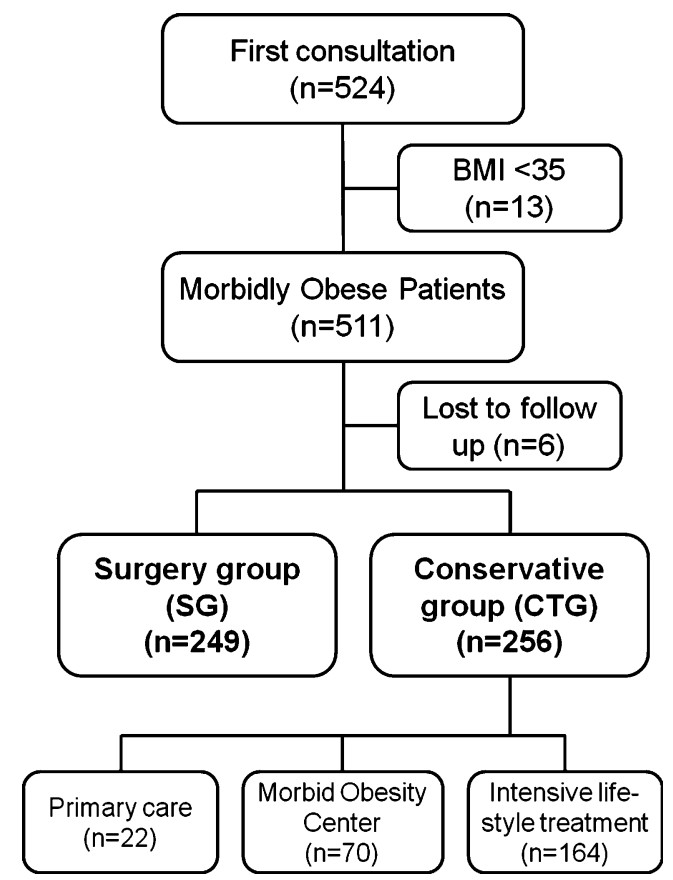

Fig. 1 Flowchart of patients and treatment choice

\section{Definitions}

Type 2 diabetes was diagnosed in patients who had either a prior history of type 2 diabetes or a fasting serum glucose level $\geq 7.0 \mathrm{mmol} / 1$ [18]. Patients with previously diagnosed hypertension and patients with blood pressure $\geq 140 / 90 \mathrm{mmHg}$ were categorized as having hypertension. Dyslipidemia was defined as elevated fasting triglycerides $(\geq 1.7 \mathrm{mmol} / \mathrm{l})$ and/or reduced HDL-cholesterol $(<1.0 \mathrm{mmol} / 1$ in men and $<1.3 \mathrm{mmol} / 1$ in women). Age at onset of obesity was recorded as either before 12 years, between 12 and 20 years, or after the age of 20 .

\section{Physical Examination}

Patients, wearing light clothing and no shoes, were measured for weight and height and BMI subsequently calculated $\left(\mathrm{kg} / \mathrm{m}^{2}\right)$. Waist circumference was measured at the level midway between the lowest rib margin and the iliac crest. Hip circumference was measured and waist/hip ratio calculated. After at least $5 \mathrm{~min}$ rest and while seated in an upright position, blood pressure was measured with an appropriately sized cuff. Three measurements were made and the average of the second and third was used in the analyses.

\section{Statistical Methods}

Data are given as either mean (SD), median, or proportions unless otherwise stated. Differences between groups were analyzed using independent samples $t$ test (continuous data) and $\chi^{2}$ (categorical data). Multiple logistic regression with predefined explanatory variables was used to assess whether a patient would opt for bariatric surgery or not (yes/no). Hosmer Lemeshow test was used to assess the adequacy of the fit of the logistic regression models. We fitted five separate logistic regression models. First (model 1; unadjusted), BMI was entered as a categorical variable (level $0=<40 \mathrm{~kg} / \mathrm{m}^{2}$ [reference], level $1=40-50 \mathrm{~kg} / \mathrm{m}^{2}$, and level $2=\geq 50 \mathrm{~kg} / \mathrm{m}^{2}$ ) in a univariate logistic regression analysis with bariatric surgery (yes/no) as the dependent variable. Second (model 2), the effect of BMI was adjusted for gender and age in a multiple logistic regression analysis. Third (model 3) onset of obesity categorized as $<12$ years, $12-20$ years, or $>20$ years (reference), was added to model 2. Fourth (model 4), the number of obesity-related comorbidities (type 2 diabetes, yes $=1$, no $=0$; hypertension, yes $=1$, no $=0$; obstructive sleep apnea, yes $=1$, no $=0$; dyslipidemia, yes $=1$, no $=0$; and joint pain; yes $=1$, no $=0$ ) were added to model 3 as a continuous variable. Finally, type 2 diabetes (yes/no) replaced number of comorbidities in model 4 (model 5). A 5\% statistical significance level was chosen. The analyses were implemented using SPSS 16.0 (SPSS, Chicago, IL, USA).

\section{Results}

Demographic and clinical characteristics from the first consultation are shown in Table 1 .

Age

Patients in the SG were on average 3 years younger than patients in the CTG. The proportion of patients, within various age groups, offered surgery or conservative treatment is shown in Fig. 2. In addition, patients in the surgery group were characterized by a lower age at onset of obesity (Fig. 3): 40\% were obese before the age of 12 compared to $26 \%$ in the conservative group ( $p=0.001$ ).

\section{Body Weight}

On average, the SG had a $9 \mathrm{~kg}$ higher body weight than the CTG (Table 1). Approximately one quarter of the patients with BMI $<40 \mathrm{~kg} / \mathrm{m}^{2}$ underwent bariatric surgery, as did half of the patients with a BMI of $40-50 \mathrm{~kg} / \mathrm{m}^{2}$ and more than two thirds of the patients with a BMI $>50 \mathrm{~kg} / \mathrm{m}^{2}$ (Fig. 4).

Among patients with a BMI $<40 \mathrm{~kg} / \mathrm{m}^{2}$ the proportion with type 2 diabetes who underwent surgery was significantly higher than those who were nondiabetic ( $36 \%$ vs. $24 \%, p=0.031)$. By contrast, diabetic status was not a significant variable in the explanation of the treatment choices made by patients with BMI $>40 \mathrm{~kg} / \mathrm{m}^{2}$ (data not shown). 
Table 1 Demographic and clinical characteristics

Data are means (SD) for continuous variables and $n(\%)$ for categorical variables

\begin{tabular}{lcrr}
\hline & SG $(n=249)$ & CTG $(n=256)$ & $p$ value \\
\hline Female & $180(72 \%)$ & $173(68 \%)$ & 0.304 \\
Age (years) & $41(11)$ & $44(13)$ & 0.002 \\
BMI $\left(\mathrm{kg} / \mathrm{m}^{2}\right)$ & $46.5(6.2)$ & $43.2(5.5)$ & $<0.001$ \\
Body weight $(\mathrm{kg})$ & $136(23.2 ;$ range $90-226)$ & $127(20.5 ;$ range $82-200)$ & $<0.001$ \\
Waist circumference $(\mathrm{cm})$ & $136(15)$ & $131(14)$ & $<0.001$ \\
Hip circumference $(\mathrm{cm})$ & $137(12)$ & $133(15)$ & $<0.001$ \\
Waist-to-hip ratio & $1.00(0.10)$ & $1.00(0.10)$ & 0.696 \\
Maximum weight $(\mathrm{kg})$ & $143(24)$ & $134(23)$ & $<0.001$ \\
Max weight, age (years) & $38(11)$ & $41(14)$ & 0.057 \\
Previous bariatric surgery & $11(4 \%)$ & $5(2 \%)$ & 0.135 \\
\hline
\end{tabular}

Obesity-Related Comorbidities and Medication

Table 2 shows that the two treatment groups were comparable with respect to the prevalence of coronary heart disease, type 2 diabetes, hypertension, obstructive sleep apnea, current smoking, pulmonary disease, and medication. Notably, the prevalence of type 2 diabetes was $23 \%$ in both groups, while the proportion of patients using various number of antidiabetic drugs did not differ significantly between groups. Similarly, approximately half the patients within both groups had hypertension, with the usage of antihypertensive drugs not differing significantly.

\section{Logistic Regression Analyses-Odds for Having Surgery}

In both the univariate (1) and multiple logistic regression models (2-5) increasing BMI levels were associated with significantly higher odds for having surgery (Table 3 ). When compared to those patients with a BMI $<40 \mathrm{~kg} / \mathrm{m}^{2}$ (reference), those with either a BMI between 40 and 50 or a BMI above $50 \mathrm{~kg} / \mathrm{m}^{2}$ were three to six times more likely to undergo bariatric surgery, even after adjustments for gender,

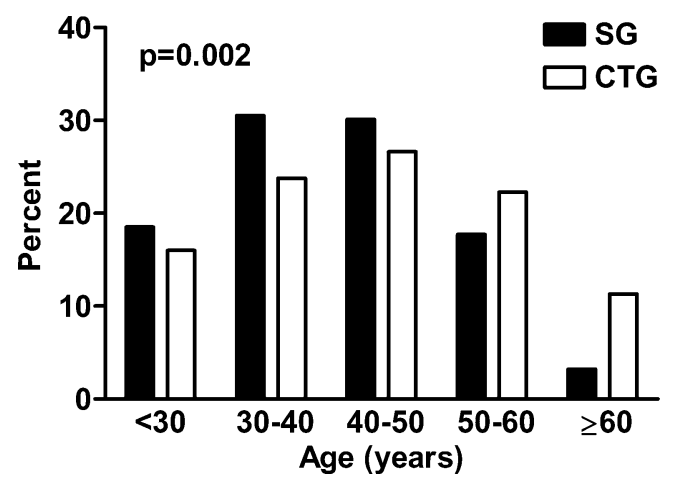

Fig. 2 Age. Distribution of the patients in the surgery group $(S G)$ and the conservative treatment group $(C T G)$ according to age The chisquare test was used for statistical analysis age, age at onset of obesity, and the number of weightrelated comorbidities.

Furthermore, the full model (model 4) shows that both lower age and age at onset of obesity $<12$ years were associated with higher odds for surgery. Each yearly increase in age was associated with a $4 \%$ less chance of a patient opting for surgery. A history of childhood obesity was associated with a $61 \%$ increased odds for surgery (adulthood obesity reference). Male patients tended to opt for surgery less than females (OR 0.68, 95\% CI 0.45-1.03). As illustrated in model 4 and 5 , neither the number of weight-related comorbidities nor the presence of type 2 diabetes predicted treatment choice.

\section{Discussion}

The major finding from our study of a population of treatment seeking morbidly obese patients is that increasing levels of BMI, early onset of obesity and younger age, rather than obesity-related comorbidities, were associated with the increased likelihood of a patient opting for bariatric surgery.

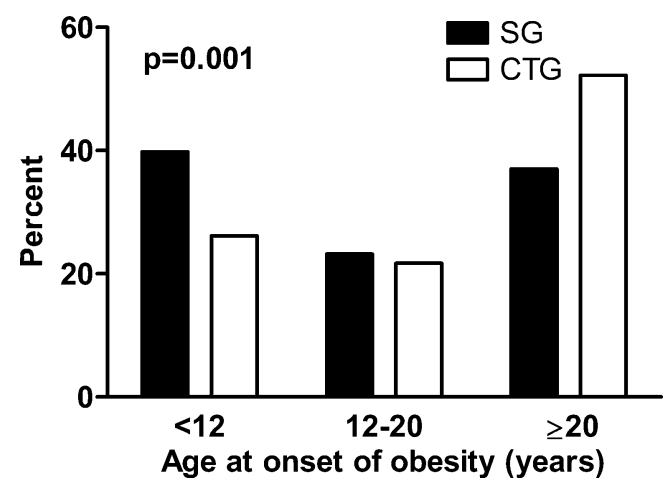

Fig. 3 Age at onset of obesity. Distribution of the patients in the surgery group $(S G)$ and the conservative treatment group $(C T G)$ according to age at onset of obesity. The chi-square test was used for statistical analysis 


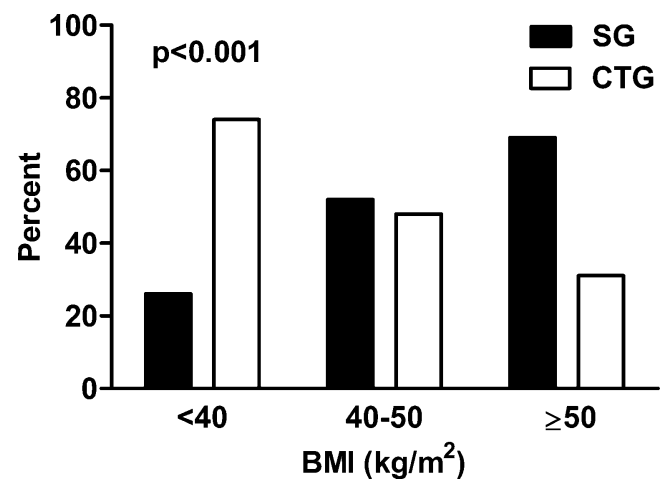

Fig. 4 BMI. Proportion of patients within each BMI category who underwent surgery $(S G)$ or received conservative treatment $(C T G)$. The chi-square test was used for statistical analysis

Obesity-Related Comorbidities were not Associated with Treatment Choice

It is well known that obesity-related comorbidities such as type 2 diabetes and obstructive sleep apnea either improve or resolve after bariatric surgery. As such, the existence of any serious obesity-related comorbidity in a morbidly obese patient supports surgery as an appropriate treatment choice. In light of this, we were surprised by the overall absence of a relationship between obesity-related comorbidities and treatment choice (except among patients with a BMI $<40 \mathrm{~kg} / \mathrm{m}^{2}$ in which surgery was more often chosen by patients with type 2 diabetes than those without diabetes). This finding might have several explanations. First, although several lines of evidence indicate that laparoscopic bariatric surgery is associated with low death and complication rates, surgery still is a serious intervention that can be fatal. Accordingly, concerns about surgical complications might have favored a conservative treatment choice among patients with serious comorbidities. Second, all patients who receive conservative treatment are informed that surgery might be an option later on if the conservative approach fails. Thus, patients initially choosing a conservative treatment strategy might request bariatric surgery in the future. Third, our tertiary care clinic offers a variety of conservative treatment strategies including individual or group-based behavioral therapy programs, either in our outpatient clinic or at weight loss camps, which might have been attractive despite previous treatment failures. Fourth, until very recently, official diabetes guidelines have not acknowledged that type 2 diabetes may be one of the most important indications for bariatric surgery. However, the latest guidelines from both the Norwegian Directorate of Health and the American Diabetes Association (2009) recommend that "Bariatric surgery should be considered for adults with a BMI $\geq 35 \mathrm{~kg} / \mathrm{m}^{2}$ and type 2 diabetes, especially if the diabetes is difficult to control with lifestyle and pharmacologic therapy" [19]. In light of this we will thoroughly reassess and scrutinize our routines to ensure that all patients receive balanced and updated information concerning the beneficial effects of bariatric surgery on type 2 diabetes. Finally, differences in quality of life [20] and internalized prejudices against surgical treatment of a "lifestyle-induced" disease might have influenced the choice of therapy.

Weight Significantly Affected the Likelihood of a Patient Opting for Surgery

It has recently been argued that patients with a BMI $>50 \mathrm{~kg} / \mathrm{m}^{2}$, and particularly patients with a BMI $>50 \mathrm{~kg} / \mathrm{m}^{2}$ and type 2 diabetes, should be referred to bariatric surgery as "best practice" [16] and as a "standard treatment option" [21]. Our results partly concur with these suggestions to the extent that they show that patients with a BMI $>50 \mathrm{~kg} / \mathrm{m}^{2}$ were six times more likely to have surgery than those with a BMI between 35 and $40 \mathrm{~kg} / \mathrm{m}^{2}$. Approximately, one quarter of patients with a BMI $<40$ underwent bariatric surgery, as did half the patients with a BMI between 40 and 50 and more than two thirds of the patients with a BMI greater than $50 \mathrm{~kg} / \mathrm{m}^{2}$.

Table 2 Comorbidities and drug therapy according to treatment choice

\begin{tabular}{|c|c|c|c|}
\hline & $\begin{array}{l}\text { SG } \\
(n=249)\end{array}$ & $\begin{array}{l}\text { CTG } \\
(n=256)\end{array}$ & $p$ value \\
\hline Type 2 diabetes & $57(23 \%)$ & $58(23 \%)$ & 1.000 \\
\hline Antidiabetic drugs & $44(18 \%)$ & $36(14 \%)$ & 0.332 \\
\hline \multicolumn{4}{|l|}{ No. of drugs } \\
\hline 1 & $25(10 \%)$ & $16(6 \%)$ & \multirow[t]{2}{*}{0.388} \\
\hline$\geq 2$ & $19(8 \%)$ & $21(8 \%)$ & \\
\hline Hypertension & $127(51 \%)$ & $136(53 \%)$ & 0.698 \\
\hline Antihypertensive drugs & $79(32 \%)$ & $89(35 \%)$ & 0.529 \\
\hline \multicolumn{4}{|l|}{ No of drugs } \\
\hline 1 & $34(14 \%)$ & $41(16 \%)$ & \multirow{3}{*}{0.877} \\
\hline 2 & $25(10 \%)$ & $27(11 \%)$ & \\
\hline$\geq 3$ & $20(8 \%)$ & $21(8 \%)$ & \\
\hline Obstructive sleep apnoea & $36(15 \%)$ & $45(18 \%)$ & 0.404 \\
\hline Asthma & $55(22 \%)$ & $52(20 \%)$ & 0.704 \\
\hline COPD & $9(4 \%)$ & $9(4 \%)$ & 1.000 \\
\hline Asthma and/or COPD & $62(25 \%)$ & $58(23 \%)$ & 0.626 \\
\hline Asthma and COPD (drugs) & $53(21 \%)$ & $45(18 \%)$ & 0.347 \\
\hline Joint pain & $155(62 \%)$ & $150(59 \%)$ & 0.454 \\
\hline Pain killers & $70(28 \%)$ & $57(22 \%)$ & 0.158 \\
\hline Hyperlipidemia & $180(72 \%)$ & $168(66 \%)$ & 0.128 \\
\hline Statins & $27(11 \%)$ & $32(13 \%)$ & 0.659 \\
\hline Anxiety/depression & $88(35 \%)$ & $102(40 \%)$ & 0.314 \\
\hline Coronary heart disease & $10(4 \%)$ & $16(6 \%)$ & 0.350 \\
\hline Current smoking & $74(30 \%)$ & $66(25 \%)$ & 0.484 \\
\hline
\end{tabular}

Data are $n(\%)$

$C O P D$ chronic obstructive pulmonary disease 


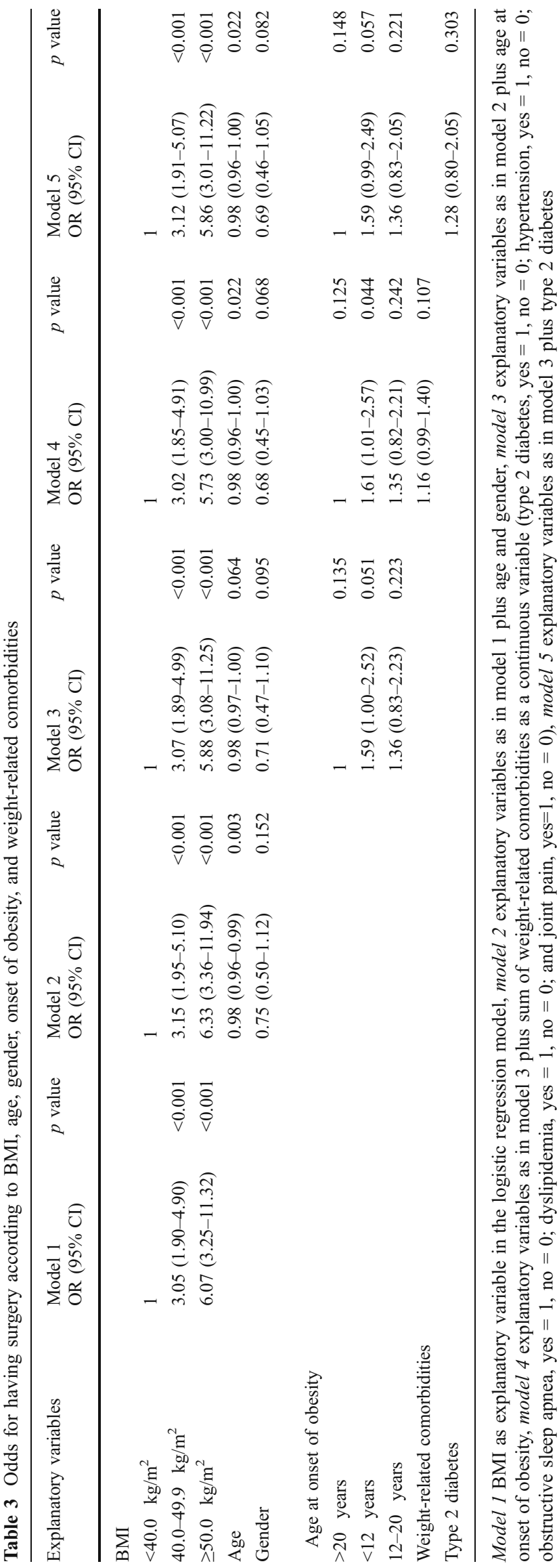

Age

Another factor to be considered when prioritizing patients for bariatric surgery is age. There has been partial agreement, but also much debate, about an upper agelimit for bariatric surgery $[22,23]$. The current European guidelines suggest that "bariatric surgery above age 60 years should be considered on an individual basis". Our study can be seen to have cohered with these guidelines given that only a small proportion (3\%) of the patients in the surgery group were above 60 years of age. The majority of patients $>60$ years received conservative treatment.

\section{Strengths and Limitations}

The validity of our findings is strengthened by the fact that they emerged from the prospective collection and registration of data from a relatively large population of treatment seeking morbidly obese individuals. In addition, the associations between explanatory variables and treatment choice remained robust even after adjustments for relevant confounding variables.

Our study had several limitations. First, the cross-sectional design made it impossible to establish a cause-effect relationship. Second, our results may not be valid in nonwhite populations. Third, we cannot exclude the possibility that referral of patients to a tertiary care center might have introduced a sampling bias limiting the generalizability of our results. Fourth, although our multidisciplinary team aims to provide the patients with objective and balanced information about the various treatment alternatives, we cannot exclude the possibility of selection bias.

Finally, we have not addressed psychological factors which also may influence the choice of treatment. However, a recent Swedish study of patients choosing between surgery and conservative treatment showed there to be no significant differences in psychological disturbances [24].

\section{Conclusion}

Our results indicate that increasing levels of BMI rather than obesity-related comorbidities, predicted treatment choice in morbidly obese patients. To our knowledge this is the first study to address the effect of somatic comorbidities on the treatment choices of morbidly obese patients. As such, our findings should be validated by others.

Funding Gunn Signe Jakobsen has received an unrestricted educational grant from Vestfold Hospital Trust. Dag Hofsø has received unrestricted educational grants from Novo Nordisk A/S, South-Eastern Norway Regional Health Authority and Vestfold Hospital Trust. 
Conflict of interest The authors declare that they have no conflict of interest.

Open Access This article is distributed under the terms of the Creative Commons Attribution Noncommercial License which permits any noncommercial use, distribution, and reproduction in any medium, provided the original author(s) and source are credited.

\section{References}

1. Ogden CL, Carroll MD, Curtin LR, et al. Prevalence of overweight and obesity in the United States, 1999-2004. JAMA. 2006;295(13):1549-55.

2. Ulset E, Undheim R, Malterud $\mathrm{K}$. Has the obesity epidemic reached Norway? Tidsskr Nor Laegeforen. 2007;127(1):34-7.

3. Whitlock G, Lewington S, Sherliker P, et al. Body-mass index and cause-specific mortality in 900000 adults: collaborative analyses of 57 prospective studies. Lancet. 2009;373(9669):1083-96.

4. Buchwald H, Avidor Y, Braunwald E, et al. Bariatric surgery: a systematic review and meta-analysis. JAMA. 2004;292(14):1724-37.

5. Sjostrom L, Narbro K, Sjostrom CD, et al. Effects of bariatric surgery on mortality in Swedish obese subjects. N Engl J Med. 2007;357(8):741-52.

6. Adams TD, Gress RE, Smith SC, et al. Long-term mortality after gastric bypass surgery. N Engl J Med. 2007;357(8):753-61.

7. Christiansen T, Bruun JM, Madsen EL, et al. Weight loss maintenance in severely obese adults after an intensive lifestyle intervention: 2- to 4-year follow-up. Obesity (Silver Spring). 2007;15(2):413-20.

8. Anderson JW, Conley SB, Nicholas AS. One hundred pound weight losses with an intensive behavioral program: changes in risk factors in 118 patients with long-term follow-up. Am J Clin Nutr. 2007;86(2):301-7.

9. Richelsen B, Tonstad S, Rossner S, et al. Effect of orlistat on weight regain and cardiovascular risk factors following a verylow-energy diet in abdominally obese patients: a 3-year randomized, placebo-controlled study. Diabetes Care. 2007;30(1):27-32.

10. Rucker D, Padwal R, Li SK, et al. Long term pharmacotherapy for obesity and overweight: updated meta-analysis. BMJ. 2007;335 (7631):1194-9.
11. Williamson DA, Rejeski J, Lang W, et al. Impact of a weight management program on health-related quality of life in overweight adults with type 2 diabetes. Arch Intern Med. 2009;169 (2):163-71.

12. Pi-Sunyer X, Blackburn G, Brancati FL, et al. Reduction in weight and cardiovascular disease risk factors in individuals with type 2 diabetes: one-year results of the look AHEAD trial. Diabetes Care. 2007;30(6):1374-83.

13. Gastrointestinal surgery for severe obesity. National institutes of health consensus development conference statement. Am J Clin Nutr. 1992;55(2 Suppl):615S-19.

14. Fried M, Hainer V, Basdevant A, et al. Interdisciplinary European guidelines for surgery for severe (morbid) obesity. Obes Surg. 2007;17(2):260-70.

15. Buchwald $\mathrm{H}$. Consensus conference statement bariatric surgery for morbid obesity: health implications for patients, health professionals, and third-party payers. Surg Obes Relat Dis. 2005;1(3):371-81.

16. Dixon JB. Referral for a bariatric surgical consultation: it is time to set a standard of care. Obes Surg. 2008;19(5):641-4.

17. http://www.helsenord.no/getfile.php/RHF/Fagutvikling/Dokumenter/ Rapport\%20sykelig\%20overvekt \%20voksne\%201.11.2007.pdf

18. American Diabetes Association. Diagnosis and classification of diabetes mellitus. Diabetes Care. 2009;32 Suppl 1:S62-7.

19. American Diabetes Association. Standards of medical care in diabetes-2009. Diabetes Care. 2009;32 Suppl 1:S13-61.

20. Stout AL, Applegate KL, Friedman KE, et al. Psychological correlates of obese patients seeking surgical or residential behavioral weight loss treatment. Surg Obes Relat Dis. 2007;3 (3):369-75.

21. Purnell JQ, Flum DR. Bariatric surgery and diabetes: who should be offered the option of remission? JAMA. 2009;301(15): $1593-5$.

22. Fatima J, Houghton SG, Iqbal CW, et al. Bariatric surgery at the extremes of age. J Gastrointest Surg. 2006;10(10):1392-6.

23. Marsk R, Freedman J, Tynelius P, et al. Antiobesity surgery in Sweden from 1980 to 2005: a population-based study with a focus on mortality. Ann Surg. 2008;248(5):777-81.

24. Elfhag K, Wiren M. Those who themselves choose bariatric surgery are the most suitable candidates. The intervention requires life-long adaptation, important to check if the patient is up to it. Lakartidningen. 2007;104(18):1406-8. 